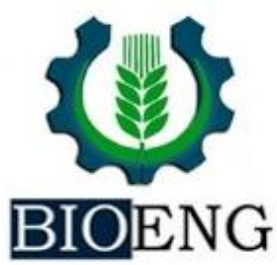

\section{AVALIAÇÃO DO CONSUMO DE COMBUSTÍVEL DE UM CONJUNTO MOTOMECANIZADO NO MANEJO DE PLANTAS DANINHAS NA CULTURA DA ACEROLA (Malpighia Ermaginata) EM CULTIVO ORGÂNICO}

\author{
${ }^{1}$ UFC - Univ Federal do Ceará, Agronomia, Fortaleza, CE, Brasil \\ ${ }^{2}$ UFC - Univ Federal do Ceara, Departamento de Engenharia Agrícola, Fortaleza, CE, \\ Brasil
}

Article history: Received 04 July 2017; Received in revised form 30 August 2017; Accepted 31 August 2017; Available online 29 September 2017.

\title{
RESUMO
}

A cultura da acerola possui grande importância para a fruticultura do país, principalmente na região Nordeste, onde primeiro a cultura foi estabelecida comercialmente no Brasil pela Universidade Rural de Pernambuco em 1955. O controle de plantas daninhas é de suma importância para o bom desenvolvimento das culturas, em culturas perenes esse controle é em grande parte viável pelo método mecânico, como roçadoras, pois as entre linhas de plantios possuem um espaçamento necessário para o conjunto trator-implemento realizar tal processo, esse método mostra o mais viável, quando comparado com o de controle manual e químico, pois o maquinário consegue tratar uma área superior da atividade realizada manualmente pelo homem e do ponto de vista ambiental, não faz-se o uso de substâncias perigosas ao ambiente como são os herbicidas usados no tratamento químico de plantas daninhas. O presente trabalho objetivou avaliar o consumo de combustível em um conjunto trator-roçadora, com três tipos de roçadoras e quatro diferentes combinações de marcha e rotação, nas entre linhas de plantio em um pomar de produção orgânica de acerola no município de Ubajara no estado do Ceará. Os resultados mostraram que houve diferença significativa nos consumos dos tratamentos testados, o que demonstra a importância desse tipo de testes visando à economia em operações mecanizadas.

Palavras-chave: eficiência energética; Capacidade de Campo; Roçadora; Rotação.

\section{FUEL CONSUMPTION OF A TRACTOR ROTARY CUTTER IMPLEMENTED IN WEED MANAGEMENT IN ORCHARD OF BARBADOS-CHERRY (Malpighia Ermaginata) IN ORGANIC FARMING}

\begin{abstract}
The culture of acerola has great importance for the country's fruit growing, mainly in the Northeast, where first the crop was established commercially in Brazil by the Rural University of Pernambuco in 1955. The control of weeds is of paramount importance for the good development of the cultures, In perennial crops this control is largely viable by the mechanical method, such as brushcutters, because the between planting lines have a necessary spacing for the tractor-implement set to perform such a process, this method shows the most viable, when compared to Manual and chemical control, since the machinery manages to treat

santos@alu.ufc.br
\end{abstract}


a superior area of the activity carried out manually by the man and from the environmental point of view, does not make use of dangerous substances to the environment as the herbicides used in the chemical treatment of weeds. The objective of this study was to evaluate the fuel consumption in a tractor-chopper assembly, with three types of brushcutter and four different combinations of gear and rotation, among the planting lines in a orchard of organic production of acerola in the municipality of Ubajara in the state of Ceará. The results showed that there was a significant difference in the consumptions of the treatments tested, which demonstrates the importance of this type of tests aiming at the economy in mechanized operations.

Keywords: Energy efficiency; Field Capacity; Slitter; Rotation.

\section{INTRODUÇÃO}

A cultura da acerola (Malpighia emarginata D.C.) é de grande relevância para a fruticultura do Brasil principalmente na região Nordeste e nos últimos anos seu cultivo vem se expandido em todo o país. A acerola é uma fruta tropical com origem na América Central, chegou ao Brasil por volta da década de 50 e teve seu cultivo intensificado na região Nordeste a parti dos anos 60, após pesquisas e implantação de áreas de cultivo pela Universidade Federal Rural de Pernambuco no ano de 1955 (EMBRAPA, 2012).

As frutíferas perenes e semi-perenes necessitam do manejo permanente das plantas e do ambiente que compõem o pomar. O cultivo de frutíferas perenes requer alto investimento e para se tornar lucrativa necessita se ter altas produtividades (MATHEIS, 2004).

Dentre estes tratos culturais manejo da irrigação, fertilização, poda, controle de pragas, doenças o controle de plantas daninhas da área, principalmente nas entre linhas de plantio, é de extrema importância para o sucesso do pomar (HAMMERMEISTER, 2016).

Segundo Leite Júnior \& Mohan, 1990 as plantas daninhas podem interferir negativamente no desenvolvimento de frutíferas por competir por nutrientes, água e liberarem substâncias alelopáticas, assim como em muitos casos, são hospedeiras de doenças e pragas.

Os manejos de plantas daninhas podem ser de três tipos: preventivas, erradicação (pouco viável em cultivos perenes) e de controle. A preventiva visa impedir a chegada de plantas daninhas a área de produção, erradicação é um método que se mostra produtivo somente para pequenas áreas de plantio, consistindo na eliminação de propágulos existentes na área. $\mathrm{O}$ controle é a manutenção das plantas daninhas em proporções reduzidas que tornem sustentável o cultivo da cultura desejada, através de medidas físicas, culturais, biológicas, mecânicas e químicas (IAP, 1992).

O método de controle de plantas daninhas mecânico em culturas perenes pode ser feito através do controle manual, capina manual, cultivo mecanizado com tração animal ou trator, no cultivo mecanizado o implementos mais utilizados é a roçadora (OLIVEIRA JÚNIOR et al, 20011).

Sistemas agrícolas mecanizados agrícolas, com conjuntos de equipamentos, máquinas e implementos usados na implantação, manejo e colheita de culturas comerciais, podem ser considerados como um importante ponto para gerenciar a redução dos custos operacionais, pois ele pode representar, pois dependendo da cultura, de 20 a $40 \%$ dos custos de produção (PACHECO, 2000).

O consumo de combustíveis fosseis na agricultura incrementa a concentração de gases poluentes na atmosfera, pois liberam principalmente dióxido de carbono e óxidos de nitrogênio. O consumo de combustível está diretamente relacionado com as atividades agrícolas requeridas (GONZALEZ-DE-SOTO et al., 2015). 
Os testes em campo com o maquinário de uma propriedade são preponderantes para eliminarmos atividades que estejam sendo onerosas para o processo e para as finanças do produtor (FERREIRA, 2003).

Segundo PARK et al. (2010) a escolha correta das configurações do motor para cada tipo de operação, impacta diretamente no tempo de vida de peças e no desempenho operacional da máquina.

A combinação correta de maquinário e implemento acarreta no aumento de eficiência de operação assim como diminuição dos custos com operações agrícolas (METAH; SELVAN, 2011).

Nota-se um déficit de material científicos e técnicos, envolvendo operações mecânicas de tratos

\section{METODOLOGIA}

O experimento foi realizado na fazenda da Empresa Amway Nutrilite do Brasil, no município de Ubajara, estado do Ceará, na microrregião da Ibiapaba, localizada na latitude $3^{\circ} 52^{\prime} 2.82$ " S, Longitude $41^{\circ} 5,35.82$ ' W. A área está a uma altitude de $769 \mathrm{~m}$ (IBGE, 2012). O clima da região é Amw de acordo com a classificação de Köeppen. $\mathrm{O}$ solo da área onde se realizou o experimento é do tipo LATOSSOLO AMARELO Eutrófico Argissólico, conforme o sistema brasileiro fruticulturais, estando os trabalhos de análise de operação do conjunto tratorimplemento concentrada principalmente nas operações de preparo do solo (aração e gradagem).

A avaliação do desempenho operacional de tratores e implementos é de suma importância tanto para o gerenciamento do maquinário como para o fabricante (RANJBARIAN et al, 2015). O presente trabalho objetivou analisar $\mathrm{O}$ consumo de combustível de um trator de $62,5 \mathrm{kw} / 85 \mathrm{cv}$ de potência, implementado com três modelos de roçadoras, no trato do controle de plantas daninhas na cultura da acerola em sistema de cultivo orgânico e quatro diferentes combinações de macha e rotação.

de classificação de solos (EMBRAPA, 2012).

$\mathrm{Na}$ Tabela 1 estão listadas algumas especificações dos implementos (roçadoras $\mathrm{A}, \mathrm{B}, \mathrm{C})$ e do trator. A roçadora $\mathrm{C}$ é do tipo ecológica, pois lançar o material cortado para o colo das plantas servindo de matéria verde e cobertura morta para o solo. Para cada roçadora foi adotado a combinação de duas machas (B1 e B2) e duas rotações (1900 e $2000 \mathrm{rpm})$.

Tabela 1. Especificações do trator e das roçadoras utilizadas no experimento.

\begin{tabular}{|c|c|c|c|c|c|c|}
\hline & $\begin{array}{l}\text { Peso } \\
(\mathrm{kg})\end{array}$ & $\begin{array}{l}\text { Largura de } \\
\text { corte }(\mathrm{mm})\end{array}$ & $\begin{array}{c}\text { Potência mínima } \\
\text { requerida no trator } \\
(\mathrm{Kw})\end{array}$ & $\begin{array}{c}\text { Número } \\
\text { de facas } \\
\text { (n) }\end{array}$ & $\begin{array}{l}\text { Potência no } \\
\text { motor }(\mathrm{Kw})\end{array}$ & $\begin{array}{l}\text { Reserva de } \\
\text { torque }(\%)\end{array}$ \\
\hline Roçadora A & 650 & 2500 & 44,9 & 4 & N/A & N/A \\
\hline Roçadora B & 635 & 2500 & 44,1 & 4 & N/A & N/A \\
\hline Roçadora C & 640 & 2600 & 47,8 & 4 & N/A & N/A \\
\hline Trator JD 5085E & 4900 & N/A & & N/A & 62,5 & 26 \\
\hline
\end{tabular}

Na Figura 1 é apresentado o trator em ação nas entrelinhas do cultivo da acerola. 


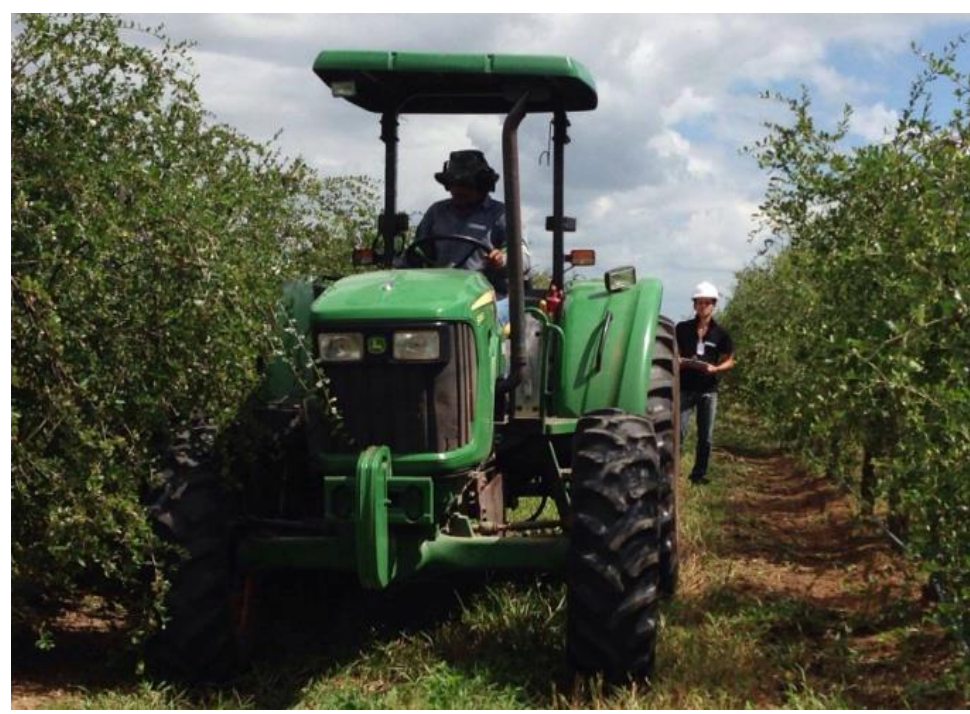

Figura 1: Trator nas entrelinhas de plantio

Para a avaliação de consumo do combustível foi utilizado um fluxômetro, Flowmate OVAL M III - LSF 41 com precisão da faixa de fluxo de $1 \%$ para mais ou para menos, vide Figura 2. Um datalogger foi utilizado em conjunto com o fluxômetro para receber os pulsos elétricos do mesmo e converter em unidades de volume de combustível que passava pelo contador mecânico, tipo engrenagem, do fluxômetro, assim como para medir o tempo em cada subparcela (repetição).

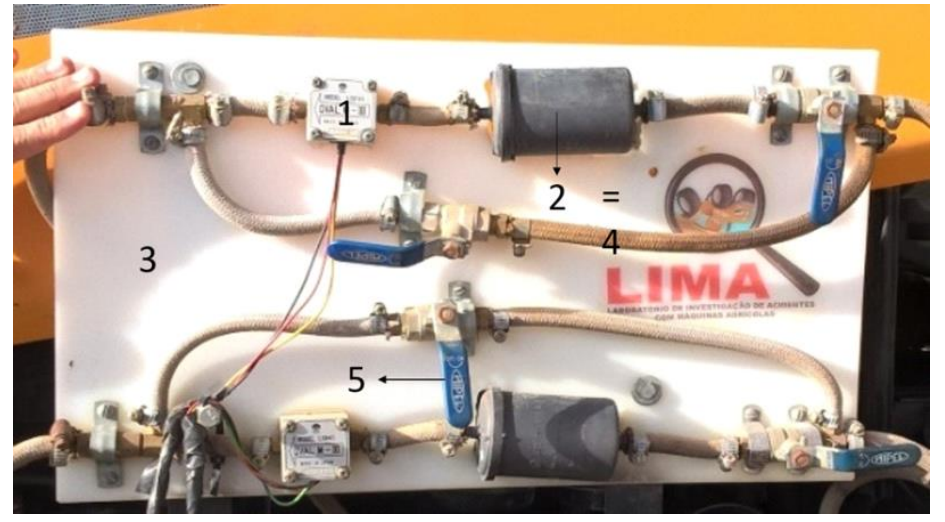

Figura 2: Fluxômetro utilizado no experimento, 1 (fluxômetro); 2 (filtro); 3 (base de plástico); 4 (mangueira de fluxo do combustível); 5 (chaves para direcionamento de fluxo)

O experimento foi implantado conforme $\mathrm{o}$ delineamento inteiramente casualizado (DIC), as parcelas foram às entrelinhas de plantio do pomar em uma área com $2 \%$ de declividade nas unidades experimentais. Foram feitas 8 repetições em cada tratamento, a computação de dados do consumo em $50 \mathrm{~m}$ de deslocamento do conjunto mecanizado e 2 $\mathrm{m}$ de largura de trabalho dos implementos, sendo assim cada parcela ocupou uma área de $800 \mathrm{~m}^{2}$.

Os dados foram submetidos ao teste de normalidade dos resíduos (SHAPIRO; WILK, 1965). Confirmada a normalidade, os dados foram analisados por ANOVA e posteriormente foi empregado o teste de Tukey para verifica se há diferença significativa entre as médias a um nível de significância de $5 \%$, por meio do programa MINITAB $^{\circledR}$ versão 17 . 


\section{RESULTADOS E DISCUSSÃO}

A Figura 3 mostra o resultado do teste de normalidade de Shapiro-Wilk. O valor $P$ acima de 0,05 evidencia normalidade nos dados coletados em campo, já que para haver normalidade, o valor $\mathrm{p}$ deve ser superior a significância adotada (LOPES et al., 2013), no caso de $5 \%$.

Os consumos para as diferentes interações dos tratamentos foram expressos em litros por hectare. Segundo KAMPHORST (2003) está é a forma ideal de representar o consumo de um maquinário agrícola, pois se considera a área trabalhada pelo implemento e a velocidade média de deslocamento do conjunto trator-implemento.

Os custos com combustível ontinuam sendo um problema mundial na agricultura mecanizada, levando pesquisadores a desenvolver novos métodos de sistemas de cultivos que minimizem o uso de combustíveis (BURT et al., 983). Mahl et al. (2004) avaliando um conjunto trator-implemento agrícola, verificaram que ao aumentar a velocidade de deslocamento do conjunto, conseguiuse incremento na capacidade de campo efetiva e redução no consumo operacional de combustível.

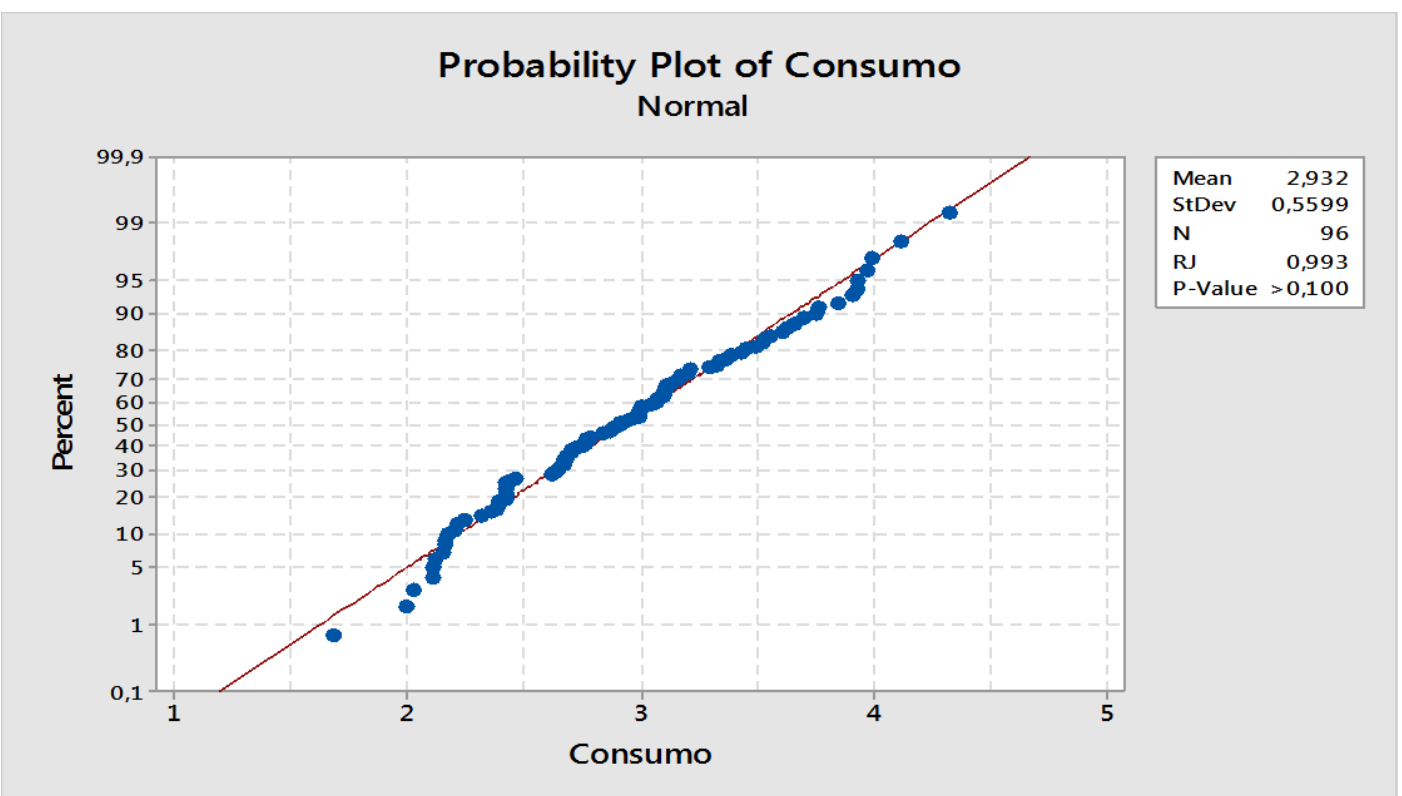

Figura 3: Gráfico de Normalidade de dados do teste de Shapiro-Wilk para consumo

Após a análise e confirmação de distribuição normal dos dados, foi realizada a análise de variância (Anova).

Os dados de consumo de combustível para os diferentes tratamentos foram submetidos à Análise de variância no software MINITAB $^{\circledR}$ e observou-se diferença significativa para a interação entre tratamentos, como mostra a Tabela 2, para a variável velocidade não houve interação. 
Tabela 2: Analise de variância (ANOVA) do consumo de combustível e velocidade * $\quad P<0,05$, significância de 5\%; ns $P>0.05, \quad$ não significante.

$\mathrm{Na}$ Tabela 3 são apresentados as médias de consumo e velocidade em litros por hectare e quilômetros por hora respectivamente, para cada tratamento.

Pode-se observar que o menor consumo foi obtido com o tratamento usando a roçadora $B$ na combinação de marcha-rotação B2-2000 rpm, esse resultado pode ser explicado justamente pela velocidade média de trabalho, alcançada pelo conjunto trator-roçadora nesse tratamento. Tal velocidade de deslocamento pode ser atribuída pela menor potência requerida na TDP do motor pela roçadora $\mathrm{B}$ em comparação com os outros implementos.
Tal velocidade está situada dentro da faixa ideal de trabalho para implementos de corte para o controle de plantas daninhas, 2 a $6 \mathrm{~km} \cdot \mathrm{h}^{-1}$ segundo MARQUEZ, (2010). Nesta faixa de velocidade a maior parte das roçadoras exercem um serviço de corte adequado, levando a uma uniformidade da altura das plantas daninhas.

O desempenho do conjunto tratorroçadora nos tratamentos com $\mathrm{o}$ fator roçadora $\mathrm{C}$ (modelo ecológico) demonstrou na média os mais altos consumos de combustível comparado com os outros tratamentos, este resultado provavelmente é em razão da maior potência de trabalho requerida por este implemento.

Tabela 3. Consumo de combustível e Velocidade em função de cada tratamento

\begin{tabular}{|c|c|c|c|c|c|c|c|}
\hline Tratamentos & \multicolumn{2}{|c|}{ Consumo } & \multicolumn{3}{|c|}{ Velocidade } & \multicolumn{2}{|r|}{$\mathrm{CcE}$} \\
\hline$A^{*} B 11900$ & \multicolumn{2}{|l|}{$3,37^{\mathrm{ab}}$} & \multicolumn{3}{|c|}{4,0} & \multicolumn{2}{|r|}{1,01} \\
\hline \multicolumn{8}{|c|}{ ANOVA } \\
\hline \multicolumn{8}{|c|}{ Consumo } \\
\hline Fonte & & Média & Coeficiente de & Variação & Desvio Padrão & $\mathrm{F}$ & $\mathrm{P}$ \\
\hline Roçadora*Ma & Rotação & 2,94 & 19,08 & & 0,56 & 3,43 & $0,004 *$ \\
\hline \multicolumn{8}{|c|}{ Velocidade } \\
\hline Roçadora*Ma & Rotação & 4,88 & 17,94 & & 0,88 & 227.92 & $0,07^{\mathrm{ns}}$ \\
\hline$A^{*} B 12000$ & $3,49^{\mathrm{a}}$ & & & 4,1 & & & 1,05 \\
\hline$A^{*} B 21900$ & $2,36^{\mathrm{de}}$ & & & 5,8 & & & 1,45 \\
\hline$A^{*} B 22000$ & $2,69^{\mathrm{cd}}$ & & & 6,0 & & & 1,50 \\
\hline $\mathrm{B} * \mathrm{~B} 11900$ & $2,67^{\mathrm{cd}}$ & & & 4,1 & & & 1,04 \\
\hline $\mathrm{B}^{*} \mathrm{~B} 12000$ & $2,82^{\mathrm{c}}$ & & & 4,3 & & & 1,08 \\
\hline B*B21900 & $2,05^{\mathrm{e}}$ & & & 5,9 & & & 1,49 \\
\hline$B * B 22000$ & $2,35^{\mathrm{de}}$ & & & 6,1 & & & 1,53 \\
\hline$C^{*} \mathrm{~B} 11900$ & $3,75^{\mathrm{a}}$ & & & 3,9 & & & 1,00 \\
\hline$C^{*} \mathrm{~B} 12000$ & $3,49^{\mathrm{a}}$ & & & 4,1 & & & 1,04 \\
\hline$C^{*} \mathrm{~B} 21900$ & $3,03^{b c}$ & & & 5,6 & & & 1,41 \\
\hline$C^{*} B 22000$ & $3,05^{\mathrm{bc}}$ & & & 5,8 & & & 1,46 \\
\hline
\end{tabular}

Médias que compartilham entre si a mesma letra não difere a um nível de significância de $5 \%$ pelo teste de Tukey. 
Quando se faz uma analise da capacidade de campo efetiva e o consumo de combustível, pode se verificar que as melhores combinações para as três roçadoras foram AB21900, AB22000, BB21900, BB22000, CB21900 e CB22000, com uma capacidade de campo efetiva superior e um menor consumo de combustível quando comparado com as demais combinações. No entanto quando

\section{CONCLUSÃO}

Concluímos que o experimento demonstrou significância suficiente para inferimos que tais testes realizados com o maquinário de uma propriedade podem levar a uma adequação da frota de

\section{AGRADECIMENTOS}

A empresa Amway Nutrilite do Brasil $^{\circledR}$ pela parceria que culminou na utilização de sua área de produção e corpo técnico como ajuda fundamental na

\section{BIBLIOGRAFIA}

BURT, E. C.; BAILEY, P. W. L.; MEIRING, P. Ballast and inflation effects on tire tractive.

Transactions ASAE, Saint Joseph, v. 26, n. 5, p. 1352-1354, 1983.

Empresa Brasileira de Pesquisa Agropecuária. Coleção plantar: acerola. Disponível em $<$ https://ainfo.cnptia.embrapa.br/digital/bit stream/item/128278>. Acesso em: 28 mar. 2017.

MATHEIS, H. A. San M. Efeitos de diferentes coberturas mortas obtidas a partir de manejo mecânico com roçadeira lateral na dinâmica populacional de plantas daninhas em citros. 2004. 68 p. Dissertação (Mestrado) - ESALQ, USP, Piracicaba, 2004. Disponível em: $<$ https://ainfo.cnptia.embrapa.br/digital/bit comparamos entre roçadoras a que apresentou um melhor desempenho foi a B na macha B2 e rotação de $2000 \mathrm{rpm}$.

Segundo Ramos, 20113 o aumento da velocidade de operação, houve aumento na capacidade efetiva bruta dos equipamentos agrícolas; porém, porém em alguns casos não há diferença estatística de desempenho entre as máquinas, exemplo das colhedoras de cana-de-açúcar .

maquinário e implementos, otimizando o serviço e diminuindo custos operacionais com mecanização agrícola pela diminuição do consumo de combustível.

realização de tal experimento. A CNPq pelo incentivo e fomento à pesquisa e geração de ciência no Brasil através da bolsa concedida.

stream/item/128278>. Acesso em: 24 mar. 2017.

OLIVEIRA JÚNIOR, R. S.; CONSTATIN, J.; INOUE, M. H. Biologia e manejo de plantas daninhas. Curitiba PR. Omnipax, 2011. 348p.

PACHECO, E. P. Seleção e custo operacional de máquinas agrícolas. Rio Branco: Embrapa Acre, 2000. 21p. (Embrapa Acre. Documentos, 58).

SHAPIRO, S. S.; WILK, M. B. An analysis of variance test for normality (complete samples). Biometrika, Londres, v. 52, n. 3-4, p. 591-611, 1965.

MEHTA, C.R.; Singh, K.; Selvan, M.M. Decision support system for selection of tractor-implement system used on Indian farms. Journal of Terramechanics, v 48, p.65-73, 2011. 
MAHL, D.; GAMERO, C.A.; BENEZ, S.H.; FURLANI, C.E.A.; SILVA, A.R.B. Demanda energética e eficiência na distribuição de sementes de milho sob variação de velocidade e condição do solo. Engenharia Agrícola, v.24, n.1, p.150-7, 2004.

RANJBARIAN, S.; ASKARI, M.; JANNATKHAH, J. Performance of tractor and tillage implements inclay soil. Journal of the Saudi Society of Agricultural Sciences, Arábia Saudita, $v$ 16. P.154-162, 2017.

RAMOS, C. R. G. Desempenho operacional da colheita mecanizada de cana-de-açúcar (saccharum spp. ) em função da velocidade de deslocamento e rotação do motor da colhedora. 2013. 82f. (Mestrado em Agronomia). Faculdade de Ciências Agronômicas da UNESP

Campus de Botucatu, São Paulo. 2013.

HAMMERMEISTER, A.M. Organic weed management in perennial fruits. Scientia Horticulturae, Canadá, v.208. p.28-42, 2016.

LEITE, R.P.J.; MOHAN, S.K. Integrated management of citrus bacterial canker disease caused by Xanthomonas campestris pv. citri in the State of Paraná, Brazil. Crop Protection, v. 9, n.1, p. 3-7, 1990.

KAMPHORST, J, S. Quanto gasta seu trator. Cultivar Maquinas, v.24, Brasil. 2003. Disponível em: < http://www.grupocultivar.com.br/artigos/q uanto-gasta-seu-trator $>$. Acesso em: 01 mai. 2017.

PARK, S.H.; KIM, Y.J.; IM, D.H.; KIM, C.K.; JANG, Y.; KIM, S.S. Analysis of factors affecting fuel consumption of agricultural tractor. Journal of Biosystems Engineering, v. 35, p.151-157, 2010.

GONZALEZ-DE-SOTO, M.; EMMI, L.; GARCIA, I.; GONZALEZ-DE-SANTOS, $P$. Reducing fuel consumption in weed and pest control using robotic tractors. Computers and Electronics in Agriculture, v.114, p.96-114, 2015.

LOPES, M.M.; BRANCO, V.B.T.F.; SOARES, J, Utilização dos testes estatísticos de Komogorov-Smirnov e ShapiroWilk para verificação da normalidade para materiais de pavimentação. Transportes v. 21, n. 1, p.59-66, 2013. 